\title{
A rare case report: unscarred uterus rupture in pregnancy with intra- abdominal missing foetal limb
}

\author{
Deepali H. Janugade ${ }^{1}$, Hemant B. Janugade ${ }^{2}$, Kruthika R. Sajjan ${ }^{1}$, Basavaraj K. Nagur ${ }^{2} *$
}

\begin{abstract}
${ }^{1}$ Department of OBGY, ${ }^{2}$ Department of Surgery, Krishna institute of medical science university, Karad-415110,
\end{abstract} Satara, Maharashtra, India

Received: 07 January 2016

Accepted: 08 February 2016

\section{*Correspondence:}

Dr. Basavaraj K. Nagur,

E-mail: sachin.nagur@gmail.com

Copyright: $\odot$ the author(s), publisher and licensee Medip Academy. This is an open-access article distributed under the terms of the Creative Commons Attribution Non-Commercial License, which permits unrestricted non-commercial use, distribution, and reproduction in any medium, provided the original work is properly cited.

\begin{abstract}
Ruptured uterus is an obstetric and surgical emergency that can lead to maternal or fetal death. Spontaneous rupture of an unscarred uterus during pregnancy is a rare occurrence. The incidence of ruptured uterus is 0.3 to $1.7 \%$ in women with scarred uterus, and 0.03 to $0.08 \%$ among women with unscarred uterus. We report a rare case of spontaneous uterine rupture at 30 weeks of gestation with missing fetal limb. Later on, after doing emergency laparotomy the missing limb was found in the abdominal cavity of the patient who had an unscarred uterus. Uterine rupture occurring in an unscarred uterus is sometimes an unpredictable event. Abdominal pain occurring on a pregnant woman should be seriously managed. Ultrasound scan and external electronic fetal monitoring should be carried out rapidly so as to diagnose the uterine rupture at the earliest.
\end{abstract}

Keywords: Ruptured uterus, Fetal death, Missing fetal limb, Preterm labour

\section{INTRODUCTION}

The normal, unscarred uterus is least susceptible to rupture. Uterine rupture in pregnancy is a rare and often catastrophic complication with a high incidence of foetal and maternal morbidity and mortality. This condition usually occurs in a scarred uterus, especially secondary to prior caesarean section, and is therefore considered a disease of multigravida. ${ }^{1}$ A few reports have indicated that a uterine rupture can occur in primigravida, although this is extremely rare. ${ }^{1,2}$ Beside caesarean section, inappropriate prostaglandin and oxytocin usage, previous instrumental abortion, vacuum extraction delivery, and vigorous fundal pressure are the other risk factors for uterine rupture. The initial signs and symptoms of uterine rupture are typically nonspecific, which makes the diagnosis difficult and sometimes delays definitive therapy. These cases are usually diagnosed intrapartum or shortly after delivery and managed with immediate repair of the usually encountered full-thickness rupture site or subtotal hysterectomy.

\section{CASE REPORT}

A 25 year old female $\mathrm{G}_{3} \mathrm{P}_{1} \mathrm{~L}_{1} \mathrm{~A}_{1}$ with a history of 7 months Amenorrhea came with complain of pain in upper abdomen, continuous in nature with severe intensity, not relieved by antacids, tocolytics, analgesics. Not associated with history of vomiting, fever, PV bleeding. Patient was taking regular antenatal care (ANC) .previous delivery was full term normal vaginal delivery which was uneventful. She also had a medical termination of pregnancy in the first trimester one year before this conception. On blood routine examination she was anemic with $\mathrm{Hb}$ of $8.0 \mathrm{gm} \%$ and other routine investigations were with in normal limit. Ultrasonography (USG) was done to rule out abruptio placenta, gestational age was corresponding to last menstrual period (LMP) 30 weeks, liquor was adequate, placenta was upper segment with grade 2 maturities and no sign of abruption noted. Pain in abdomen did not subside; patient went in preterm labour, fetal heart sound 
(FHS) not audible, intrauterine fetal death conformed by USG.

\section{Management}

Labour was augmented with misoprostol (zytotec) patient delivered a dead fetus (non-macerated) placenta was expelled completely. But fetal left lower limb was not found. There was no postpartum haemorrhage (PPH) no perineal or cervical tear noted, uterus well contracted. Patient was vitally stable post induction. Later on laprotomy was planned in the view of missing fetal parts after $1 \mathrm{hr}$. On exploration it was found that the missing limb was in the abdomen. Uterus well contracted, couvellier uterus was noted. There was rent of $2-2.5 \mathrm{~cm}$ diameter at the fundus slightly anterior aspect of the uterus, with well approximated edges and no active bleeding noted.

Second opinion taken uterine rent was sutured with vicryl no. 1 , hemostasis was confirmed fetal part removed, clot in abdomen were removed. Abdomen closed in layers. Patient tolerated the procedure well. Post-operative period was uneventful. After three years hystosalpingography was done and patient was allowed to conceive. in the following pregnancy patient presented with 34 weeks pregnancy with pain abdomen(threatened preterm labour) in the view of obstetric history emergency LSCS was done, it was uneventful uterus was found well contracted with fibrosis at the fundus after delivering the baby. Post-operative period was uneventful.

\section{DISCUSSION}

Uterine rupture is one of the most important obstetric emergencies, threatening the lives of both mother and foetus. Surgeries leading to risk of rupture include caesarean delivery or hysterotomy, previously repaired uterine rupture, and myomectomy incision involving the endometrium; however, the most common risk factor is scarred uterus from a prior caesarean delivery. ${ }^{4}$

In a review of uterine rupture cases in Nova Scotia between 1988 and 1997, Kieser and Baskett reported that in $92 \%$ of cases, uterine rupture was associated with a previous caesarean delivery.

There are two types of rupture: a) complete, where the whole thickness of the uterine wall is involved, usually occurring in an unscarred uterus, the uterine serosa together with the uterine muscular layer is perforated and thus the amniotic cavity directly communicates with the abdominal cavity and b) incomplete, where the visceral peritoneum remains intact, as seen in scar dehiscence. ${ }^{3}$ We could not categorize our case using either definition since it was somewhat different. The rupture seen in our case was complete with lower limb found in the abdominal cavity.
Uterine rupture may occur in the antepartum, intrapartum, or postpartum period, and accordingly clinical signs and symptoms vary. The most evident symptom at the antepartum period is abdominal pain. In most cases, the patient presents with vaginal bleeding; however, sometimes no bleeding is observed because haemorrhage may be only intra-abdominal. Patients with a previous scar in the upper uterine segment may present early in pregnancy and may not experience uterine contractions before rupture. The second important clinical issue is that abdominal palpation and ultrasound may be useful in detecting this condition. Although abdominal pain ${ }^{1,2}$ and non-reassuring FHR patterns, especially foetal bradycardia, have been reported to be signs of impending or actual uterine rupture in some cases.

Early surgical intervention is usually the key to successful treatment of uterine rupture. The therapeutic management is a total or subtotal hysterectomy. The suture can be performed and helps to preserve the reproductive function of patients who have never given birth with a recurrence risk of uterine rupture assessed between 4 and $19 \%$ at a subsequent pregnancy. For this reason, it has been recommended that women with a previous uterine rupture undergo an elective Caesarean delivery as soon as foetal lung maturity can be demonstrated.

\section{ACKNOWLEDGEMENTS}

We are thankful to M. C. Deshingkar, Rupali Salunkhe, Satish Damame, Vikas Nikam for their technical support.

\section{Funding: No funding sources \\ Conflict of interest: None declared \\ Ethical approval: Not required}

\section{REFERENCES}

1. Walsh CA, Baxi LV. Rupture of the primigravid uterus: a review of the literature. Obstet Gynecol Surv. 2007;62:327-34.

2. Dow M, Wax JR, Pinette MG, Blackstone J, Cartin A. Third-trimester uterine rupture without previous cesarean: a case series and review of the literature. Am J Perinatol. 2009;26:739-44.

3. Carlin A, Alfirevic Z. Intrapartum fetal emergencies. Semin Fetal Neonatal Med. 2006;11:150-7.

4. Cunningham FG, Leveno KJ, Bloom SL, Hauth JC, Rouse DJ, Spong CY et al. Uterine rupture. In: Williams obstetrics. $23^{\text {rd }}$ ed. New York: McGrawHill; 2010:573-6.

Cite this article as: Janugade DH, Janugade HB, Sajjan KR, Nagur BK. A rare case report: unscarred uterus rupture in pregnancy with intra-abdominal missing foetal limb. Int J Reprod Contracept Obstet Gynecol 2016:5:919-20. 